\title{
What are Manchester pharmacy students' perceptions of social media in education?
}

Author: Andrew Mawdsley, Lecturer in Pharmacy Practice, Manchester Pharmacy School, Manchester

Background: Pharmacy ${ }^{1}$, and medical educators ${ }^{2}$ are embracing social media. This study aimed to gauge this institution's students' opinion and experience of social media in teaching.

Method: Undergraduate students across four years $(n=623)$ were invited to take part in a survey regarding their views of social media in education.

Results: A total of 196 (31\%) responded. 180 (92\%) reported actively using social media - in particular: Facebook (79\%), Instagram (46\%), and Twitter (39\%). Students had experience with discussion boards $(79 \%)$, chat $(70 \%)$ and file sharing $(68 \%)$, but little experience of webinars (11\%). 58\% would use Facebook for studies: group work $(80 \%)$, communication $(77 \%)$, further reading $(71 \%)$, exam preparation $(68 \%)$ and peer support (67\%). 55\% welcome social media in education but, interestingly, $57 \%$ prefer to use Blackboard exclusively. $47 \%$ felt they would have concerns about privacy.

Discussion and Conclusion: Manchester students engage with social media and have educational experience with it. Students have concerns around personal privacy. Clinical educators believe social media offers advantages over drawbacks ${ }^{3}$. However, pharmacy students have reservations regarding online professionalism and confidentiality ${ }^{4}$.

\section{References}

1. Royal Pharmaceutical Society. (2014). Social media guidance for pharmacists. Retrieved March 10, 2014, from Royal Pharmaceutical Society: http://www.rpharms.com/unsecuresupport-resources/social-media-guidance.asp

2.Cartledge, P., Miller, M., \& Phillips, B. (2013). The use of social-networking sites in medical education. Medical Teacher, 35, 847-857.

3.Prescott, J., Stodart, M., Becket, G., \& Wilson, S. (2013). The experience of using Facebook as an Educational Tool. Health and Social Care Education, 1-5.

4. Prescott, J., Wilson, S., \& Becket, G. (2012). Pharmacy students want more guidelines on Facebook and online professionalism. The Pharmaceutical Journal, 25(2), 163.

Vrocharidou, A., \& Efthymiou, I. (2012). Computer mediated communication for social and academic purposes: profiles of use and university students' gratification. Computers and Education, 58(1), 609-616. 